\title{
Comparison methods of short term electrical load forecasting
}

\author{
Hartono $^{{ }^{*}}$, Arif Marifa Ahmad ${ }^{2}$, M.Sadikin ${ }^{3}$
}

\begin{abstract}
The supply of electricity that exceeds the load requirement results in the occurrence of electrical power losses. To provide the appropriate power supply to these needs, there must be a plan for the provision of electricity by making prediction or estimation of electrical load. Therefore the issue of electrical load forecasting becomes very important in the provision of efficient power. In this study, the author tries to build a model of short-term electrical load prediction using artificial neural network (ANN) with learning algorithm levenberg-marquardt (Trainlm), Bayesian regularization (Trainbr) and scaled conjugate gradient (Trainscg). Scope of research data retrieval is limited electrical load on the work area of Serang City. The results of this study show that the JST prediction of levenberg-marquardt (Trainlm) algorithm is better than the calculated prediction using Bayesian regularization (Trainbr) and scaled conjugate gradient (Trainscg) algorithms. The electric load prediction shows that the average error (Trainlm) is 3.37. Thus, it can be concluded that the electrical load prediction using the levenberg-marquardt (Trainlm) JST algorithm is more accurate than that of the Bayesian regularization (Trainbr) JST algorithm and the scaled conjugate gradient (Trainscg)
\end{abstract}

\section{Introduction}

The supply of electricity that exceeds the load requirement results in the occurrence of electrical power losses. Conversely, in case of supply shortage (supply) electricity, will result in the occurrence of blackouts. To provide the appropriate power supply to these needs, there must be a plan for the provision of electricity by making prediction or estimation of electrical load. Forecasting is the activity of predicting or predicting what will happen in the future. Forecasting is usually divided into two, namely qualitative meaning of forecasting based on data that is not in the form of numbers and quantitative means forecasting based on data in the form of numbers. Forecasting is done based on data or variables that have occurred previously systematically combined with a particular method and processed to obtain estimates in the future. Good forecasting will reduce unnecessary and unnecessary development risks in the supply of electricity to customers [1].

The best algorithm at the time to forecast the load and in the distribution of electrical energy is not deficient or overloaded so there is no loss on the provider of electrical energy. The reason of the use of artificial neural network (JST) is because ANN is able to learn the pattern of data or sample input or can do generalization, abstraction and extraction of

\footnotetext{
${ }^{1}$ Corresponding author: sallam.hartono@yahoo.com
} 
property statistics data historical data electrical load then can make prediction or forecast of big load which will come.

Neural Network or Neural Network (ANN) is an information processing system that has characteristics resembling a biological neural network. [4] Artificial neural networks are used for electric load forecasting because it can easily formulate a very flexible experience of forecasting and knowledge. Artificial neural networks have a good approximation to nonlinearity so that it can produce better error response. [3]

Figure 2.1 is an illustration of a neuron.

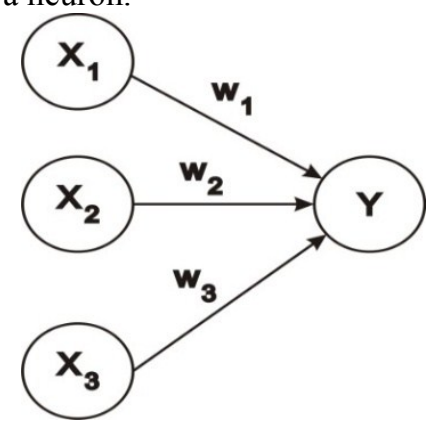

Fig. 1. Neural network 1. neuron Y artificial [4]

Y receives input from neurons $\mathrm{x} 1, \mathrm{x} 2, \mathrm{x} 3$ with the weights of each relationship are w1, w2, w3 the three implants of neurons present when summed will yield the equation:

$$
\text { net }=\mathrm{x}_{1} \mathrm{w}_{1}+\mathrm{x}_{2} \mathrm{w}_{2}+\mathrm{x}_{3} \mathrm{w}_{3}
$$

the amount of input received by $Y$ follows the activation function $y=f(n e t)$. [5]

\subsection{Backpropagation Learning Algorithm}

Artificial neural network backpropagation was first introduced by Rumelhart, Hinton and William in 1986, then Rumelhart and Mc Clelland developed it in 1988. The backpropagation algorithm for Neural network is generally applied to multi-perceptron perceptrons. Perceptron has at least an input section, an output section and several layers that are between input and output. This middle layer, also known as hidden layers, can be one, two, three and so on. In practice, the number of hidden layer at most is three layers. With these three layers almost all the problems in the industrial world have been resolved. The output of the last layer of the hidden layer is directly used as the output of the Neural network.

\subsubsection{Bayesian regularization Learning Algorithm (Trainbr)}

Bayesian regularization minimizes the linear combination of quadratic errors and weights. It also modifies the linear combination so that at the end of the training, the resulting network has good generalization qualities. Training stops when one of these conditions occurs:

1. The maximum number of epochs (repetitions) is reached.

2. Maximum amount of time exceeded.

3. Performance is minimized to destination.

4. Gradient performance drops below min_grad.

5. you exceed mu_max. 


\subsubsection{Learning Algorithm scaled conjugate gradient (Trainscg)}

The scaled conjugate gradient algorithm is a modification of backpropagation. Training stops when one of these conditions occurs:

1. The maximum number of epochs (repetitions) is reached.

2. Maximum amount of time exceeded.

3. Performance is minimized to destination.

4. Gradient performance drops below min_grad.

\subsubsection{Algoritma Pembelajaran Levenbreg-Marquardt (Trainlm)}

Like the quasi-newton method, the levenbreg-marquardt algorithm is designed using a second derived approximation without having to compute a hessian matrix. Newton method is very fast and accurate to get the minimum error, therefore the algorithm is expected as soon as possible to change the value to be equal to 0 . For that, after some iteration, this algorithm will decrease the value of $\mathrm{m}$, the increase of $\mathrm{m}$ value is only done when needed a step temporary) to decrease performance function. [7]

\section{Research methods}

The whole series for the completion of this research are as follows:

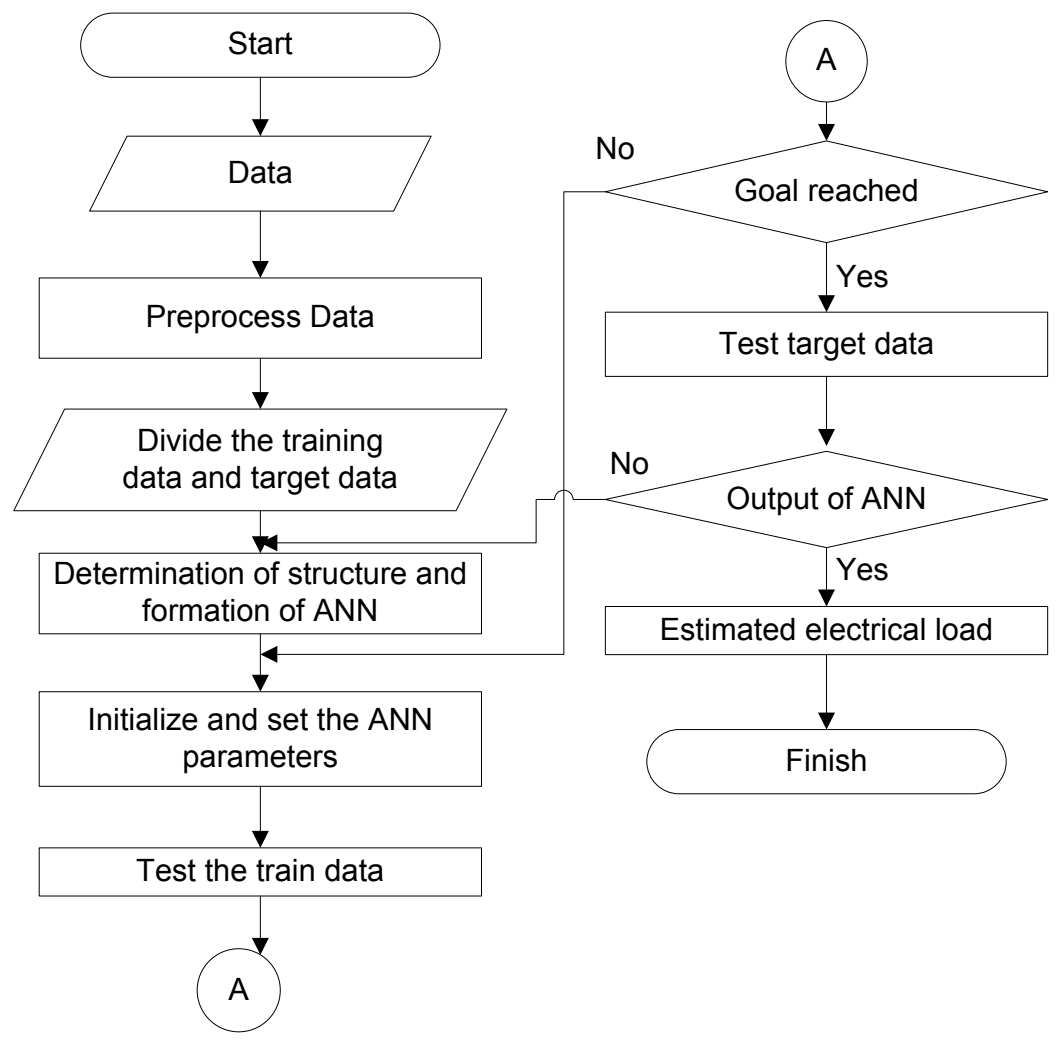

Fig. 2. Flowchart research 


\section{Results and discussion}

The following test results can be seen in the algorithm levenberg-marquardt, Bayesian regularization and scaled conjugate gradient in the figure below:

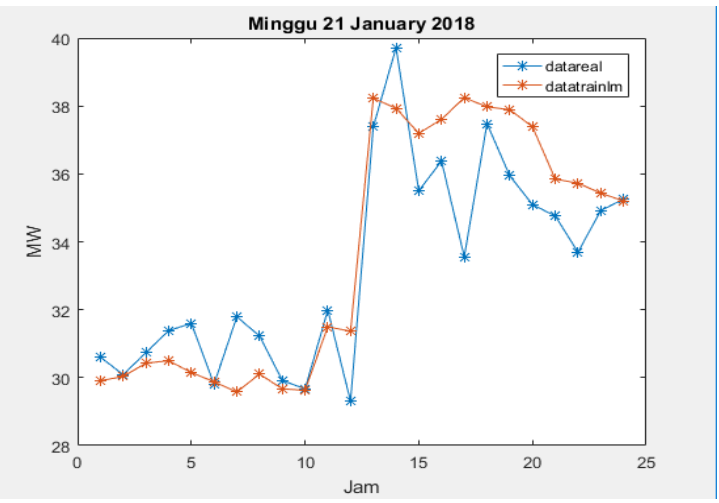

Fig. 3. Comparison of electrical trainlm expenses sunday 21 january 2018

Figure 3 shows the comparison between actual loads compared with the results of JST forecasting. Based on Figure 3.1 it is known that the largest difference between the real load and the trainlm prediction load occurs at 16.00 with a difference of $-4.6888 \mathrm{MW}$ minus sign (-) indicates that the predicted result is greater than the real load while the unmarked () is a plus which means the opposite the real burden is greater than the load of the predicted result, while thesmallest difference occurs at 23:00 which is a difference of 0.0538 MW.

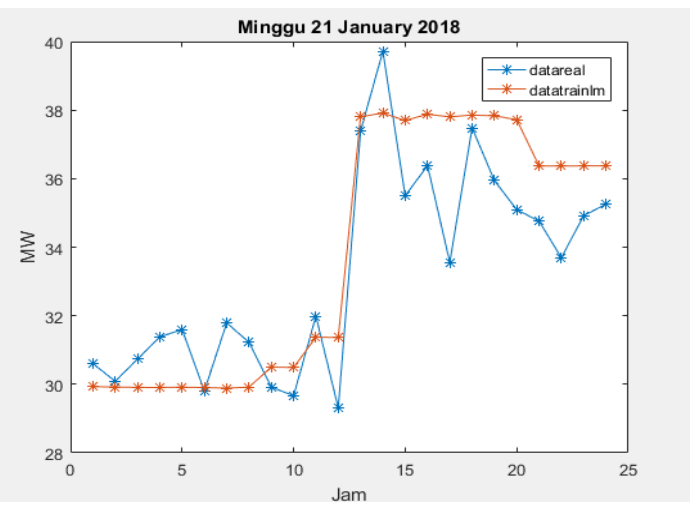

Fig. 4. Comparison of trainbr electrical weights week 21 january 2018

Based on Figure 4 it is known that the largest difference between real load and trainbred prediction load occurs at 16.00 with a difference of $-4.2442 \mathrm{MW}$ minus sign (-) indicates that the predicted result is greater than the real load while the unmarked () is a plus which means the opposite is the real burden is greater than the load of the predicted results, while the smallest difference occurs at 05.00 that is the difference of $-0.0977 \mathrm{MW}$. 


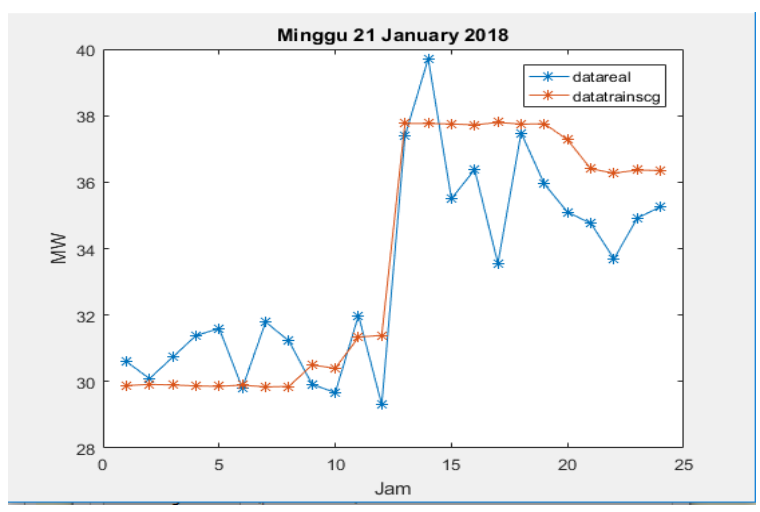

Fig. 5. Comparison of trainscg electrical expenses week 21 january 2018

Based on Figure 5 it is known that the greatest difference in real load and predicted load trainscg occurs at 16.00 with a difference of -4.2601 MW minus sign (-) indicates that the predicted result is greater than the real load while the unmarked () is a plus which means the opposite is the real burden is greater than the load of the predicted result, while the smallest difference occurs at 05.00 that is the difference of $-0.1048 \mathrm{MW}$

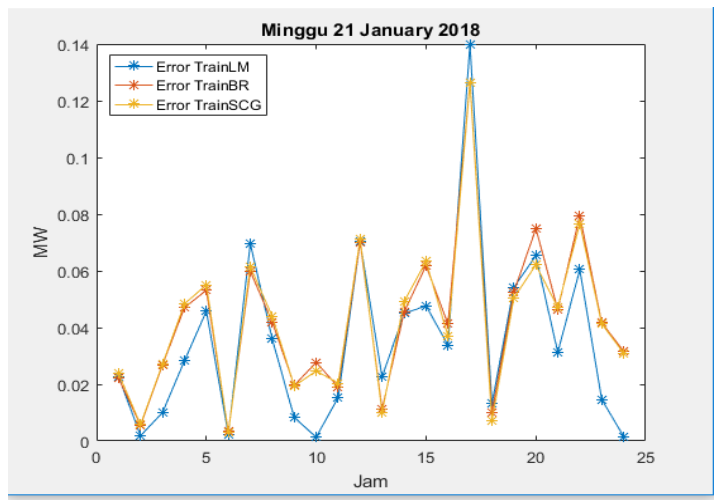

Fig. 6. Comparison of error values week 21 january 2018

Figure 6 shows the difference in load if trained in trainlm is $13.97 \%$ for the largest load at 16:00 hours while for the smallest load is $0.152 \%$ at $23: 00$, the trainbr is $12.64 \%$ for the largest load at 16:00 hours while for the smallest load is $0.32 \%$ at 05:00, and on trainscg is $12.69 \%$ for the largest load at 16:00 hours while for the smallest load is $0.0152 \%$ at $05: 00$. The average error in a day ( 24 hours) is the number of errors per hour divided by 24 so the results can be viewed in the following table 1.

Table 1. Comparison of average error sunday 21 january 2018

\begin{tabular}{|l|c|c|c|}
\hline Method & ANNTrainlm & ANNTrainbr & ANNTrainscg \\
\hline Average error & 3,503 & 4,2453 & 4,2159 \\
\hline
\end{tabular}

From the results of the average error in Table 1 each learning algorithm ANN on January 21, 2018. Apparently the prediction algorithm learning algorithm imitation levenberg-marquardt (trainlm) better than 2 learning algorithms Bayesian regularization (trainbr) and scaled conjugate gradient (trainscg ).

The following are the daily power load estimation results of Serang City on transformer 3. Using 3 artificial neural network learning algorithms namely levenberg-marquardt 
(trainlm), Bayesian regularization (trainbr) and scaled conjugate gradient (trainscg compared to actual loads) real) for January 22 - January 27, 2018 presented in tabular form

Table 2. Average error comparison dated monday 22 january 2018

\begin{tabular}{|l|c|c|c|}
\hline Method & ANN Trainlm & ANN Trainbr & ANN Trainscg \\
\hline Average error & $3.41 \%$ & $3.49 \%$ & $3.39 \%$ \\
\hline
\end{tabular}

In table 2 for Monday, January 22, 2018, the average error of prediction of neural network model of levenberg-marquardt (trainlm) is $3.41 \%$, and Bayesian regularization (trainbr) 3.49\% and scaled conjugate gradient (trainscg) of $3.39 \%$. Predicted results today show that the prediction of a scaled conjugate gradient (trainscg) JST learning algorithm is better than 2 other learning algorithms

Table 3. Average comparison of errors dated 23 tuesday january 2018

\begin{tabular}{|l|c|c|c|}
\hline Method & ANNTrainlm & ANNTrainbr & ANNTrainscg \\
\hline Average error & $3.2 \%$ & $3.6 \%$ & $3.4 \%$ \\
\hline
\end{tabular}

In Table 3 for Tuesday, January 23, 2018, the average error of predicted neural network model of Levenberg-Marquardt (trainlm) is $3.29 \%$, and Bayesian regularization (trainbr) $3.69 \%$ and scaled conjugate gradient (trainscg) of $3.46 \%$. Today's prediction results show that the learning algorithm of levenberg-marquardt (trainlm) JST learning is better than 2 other learning algorithms.

Table 4. Comparison average error date wednesday january 24, 2018

\begin{tabular}{|c|c|c|c|}
\hline Method & ANNTrainlm & ANNTrainbr & ANNTrainscg \\
\hline Average error & $3.43 \%$ & $3.98 \%$ & $3.96 \%$ \\
\hline
\end{tabular}

In Table 4 for Wednesday, January 24, 2018, the average error of prediction of neural network model of Levenberg-Marquardt (trainlm) is 3.43\%, and Bayesian regularization (trainbr) $3.98 \%$ and scaled conjugate gradient (trainscg) is $3.96 \%$. Today's prediction results show that the learning algorithm of levenberg-marquardt (trainlm) JST learning is better than 2 other learning algorithms.

Table 5. Comparison average error of 25 thursday january 2018

\begin{tabular}{|l|c|c|c|}
\hline Method & ANNTrainlm & ANNTrainbr & ANNTrainscg \\
\hline Average error & $3.24 \%$ & $3.94 \%$ & $3.25 \%$ \\
\hline
\end{tabular}

Table 5 for Thursday, January 25, 2018, the average error of prediction of neural network model of levenberg-marquardt (trainlm) is 3.24\%, and Bayesian regularization (trainbr) $3.94 \%$ and scaled conjugate gradient (trainscg) of $3.25 \%$. Today's prediction results show that the learning algorithm of levenberg-marquardt (trainlm) JST learning is better than 2 other learning algorithms

Table 6. Average comparison of errors dated 26th of january 2018

\begin{tabular}{|l|c|c|c|}
\hline Method & ANNTrainlm & ANNTrainbr & ANNTrainscg \\
\hline Average error & $3.12 \%$ & $4.5 \%$ & $4.24 \%$ \\
\hline
\end{tabular}

Table 6 for Friday, January 26, 2018, average error of prediction of neural network model of levenberg-marquardt (trainlm) is $3.14 \%$, and Bayesian regularization (trainbr) $4.5 \%$ and scaled conjugate gradient (trainscg) of $4.25 \%$. Today's prediction results show 
that the learning algorithm of levenberg-marquardt (trainlm) JST learning is better than 2 other learning algorithms

Table 7. Comparison average error of 27 saturday 2018

\begin{tabular}{|c|c|c|c|}
\hline Method & ANNTrainlm & ANNTrainbr & ANNTrainscg \\
\hline Average error & $3.56 \%$ & $5.09 \%$ & $5.14 \%$ \\
\hline
\end{tabular}

In Table 7 for Saturday, January 27, 2018, the average error of prediction of neural network model of levenberg-marquardt (trainlm) is 3.564\%, and Bayesian regularization (trainbr) $5.09 \%$ and scaled conjugate gradient (trainscg) of $5.14 \%$. Today's prediction results show that the learning algorithm of levenberg-marquardt (trainlm) JST learning is better than 2 other learning algorithms

\section{Conclusion}

1. The result of electrical power forecast for one week starting from January 21, 2018 to January 27, 2018, gives the following results:

a. The results of learning algorithm of neural network of levenberg-marquardt (trainlm) is better for January 21, January 23, January 24, January 25, January 26 and January 27, and the predicted result of scaled conjugate gradient (trainscg) is better only for the 22nd January.

b. Average error of prediction of neural network for one week (trainlm) 3,37\%, trainbr $4.13 \%$ and train $\operatorname{seg} 3.95 \%$

2. predictions using three learning methods of learning algorithm of learning algorithm of artificial neural network levenberg-marquardt (trainlm), Bayesian regularization (trainbr) and scaled conjugate gradient (trainscg) have quite accurate results. But trainlm get results faster when simulating using MATLAB.

\section{Reference}

1. D. A. Sari, "Peramalan Kebutuhan Beban Jangka Pendek Menggunakan Jaringan Syaraf Tiruan Backpropagation," Universitas Diponegoro, Semarang, (2007).

2. Fausett L. Fundamentals Of Neural Networks Architectures, Algorithmsand Applications, London: Prantice-Hall, Inc (1994).

3. I. Handayani, "Peramalan Beban Puncak Listrik Jangka Pendek Menggunakan Metode Jaringan Syaraf Tiruan," J. Sist. Kendali Tenaga Elektron. Telekomun. Komput., Vol. 1, No. 4, Pp. 2337-439, (2013).

4. Lee Ky, Park Jh. Short Term Load Forecasting Using An Artificial Neural Network, Ieee (1992)

5. Marsudi D. Operasi Sistem Tenaga Listrik, Yogyakarta: Penerbit Graha Ilmu (2006)

6. R. Dwisatya, M. R. Kirom, M. Si, A. G. Abdullah, And M. Si, "Prediksi Beban Listrik Jangka Pendek Berbasis Algoritma Feed Forward Back Propagation Dengan Mempertimbangkan Variasi Tipe Hari," Universitas Telkom, Vol. 2, No. 3, Bandung, Pp. 7315-7322, (2014)

7. S. Ruliah And R. Rolyadely, "Prediksi Pemakaian Listrik Dengan Pendekatan Back Propagation," Sekolah Tinggi Manajemen Informatika Dan Komputer Banjarbaru, Vol. 3, No. 1, Kalimantan Selatan, P. 466, (2014)

8. Triwulan Yayu, Nasrun Hariyanto And Sabat Anwari, "Peramalan Beban Puncak 
Listrik Jangka Pendek Menggunakan Metode Jaringan Syaraf Tiruan", Institut Teknologi Nasional, Vol. 1, No 4

9. Misra Soumya, Rajasree Prusty And Prados Kumar Huta. " Analysis Of LevenbergMarquardt And Scaled Conjugate Gradient Training Algorithms For Artificial Neural Network Based Ls And Mmse Estimated Channel Equalizers", (Ieee 2015 International Conference On Man And Machine Interfacing (Mami))

10. Sahay Bhushan Kishan, Sunet Sahuu And Pragya Singh " Short-Term Load Forecasting Of Toronto Canada By Using Different Ann Algorithms" , (978-1-50900128-6/16/\$31.00 (2016 Ieee)

11. Sujito, "Perhitungan Life Time Transformator Jaringan Distribusi $20 \mathrm{Kv}$ Di Apj Malang," Univeritas Negeri Malang, Malang, Pp. 63-75 (2009)

12. H. G. Nugraha And Azhari, "Pelatihan Bobot Jaringan Syaraf Tiruan Menggunakan Particle Swarm Optimization Untuk Peramalan Tingkat Inflasi," Universitas Gajah Mada, Yogyakarta, Pp. 292-302 (2014) 